\title{
Risk Manager
}

National Cancer Institute

\section{Source}

National Cancer Institute. Risk Manager. NCI Thesaurus. Code C53448.

A person trained and licensed to implement and oversight health care risk management prog rams aimed on assuring greater patient safety in health care facility or institution. The main thrust of the risk manager activity is in identifying incidents occurring in the health care organization, which have an outcome of patient injury and may reflect error in the course of the delivery of health care services, adverse incidents reporting, tracking, trending and elaboration of risk reduction and risk prevention strategies and measures. 